\title{
O Uso das Tecnologias Digitais de Informação e Comunicação em Sala de Aula pelos Professores das Escolas Municipais de uma Cidade do Sul de Minas Gerais
}

\author{
Fábio J. Alves ${ }^{1}$, Jéssica A. L. Venâncio ${ }^{1}$, Emerson A. Carvalho ${ }^{1}$ \\ ${ }^{1}$ IFSULDEMINAS - Campus Machado \\ Rodovia Machado - Paraguaçu - KM 3 - Santo Antônio - Machado - MG - Brasil \\ \{fabio.alves, emerson.carvalho\}@ifsuldeminas.edu.br, jlimavenancio@outlook.com
}

\begin{abstract}
The constant technological evolution causes changes in all society's sectors, including the educational sector. Thus, for the use of TDICs, it is necessary to know how to apply all the existing potential in the educational system, from the infrastructure to training of teachers and determination of the pedagogical components that guide the teaching and learning process at school. Considering the above, this study aims to investigate the conceptions of public school's teachers in a city in the south of Minas Gerais regarding to the use of Digital Information and Communication Technologies in their pedagogical practices in Elementary School.
\end{abstract}

Resumo. A constante evolução tecnológica provoca transformações em todos os setores da sociedade, inclusive no setor educacional. Sendo assim, para utilização das TDIC, faz-se necessário saber como aplicar todo o potencial existente no sistema educacional, desde a infraestrutura até a formação dos professores e determinação dos componentes pedagógicos que norteiam o processo de ensino e de aprendizagem escolar. Considerando o exposto, este estudo tem por objetivo investigar as concepções de professores de escolas públicas de uma cidade do sul de Minas Gerais em relação ao uso das Tecnologias Digitais da Informação e Comunicação nas suas práticas pedagógicas no Ensino Fundamental.

\section{Introdução}

A sociedade passa por um momento de ampliação das possibilidades de comunicação e de informação, por meio dos avanços e disseminação das Tecnologias Digitais de Informação e Comunicação (TDIC), por meio dos recursos tecnológicos como o telefone, a televisão, o computador entre outros; que alteram a forma de viver e de aprender dos indivíduos. Em função da evolução trazida por essas tecnologias para a sociedade contemporânea, hoje as pessoas utilizam diretamente ou indiretamente os recursos tecnológicos, seja no trabalho, em casa, na escola, no comércio etc [CGI.br. 2015]. O computador e a Internet tem sido considerados os principais recursos utilizados, pois como afirma [Neitzel 2008] "a informática superou os outros meios de comunicação, principalmente pela velocidade em que as coisas se realizam".

As TDIC chegaram como necessidade emergente da sociedade atual para finalidades, interesses e funções bastante diferenciadas. Na área educacional, os avanços tecnológicos possibilitaram mudanças que atualmente propiciam um mundo conectado, uma ampliação dos espaços de aprendizagem e modificações na maneira de aprender e 
VI Congresso Brasileiro de Informática na Educação (CBIE 2017)

Anais do XXIII Workshop de Informática na Escola (WIE 2017)

ser dos alunos. Para [Lima 2015], o aluno do século XXI deve ser incentivado a agir de maneira criativa, autônoma, sendo capaz de produzir seu próprio conhecimento.

Desse modo, pensar em como incorporar as inovações tecnológicas no ambiente educacional de forma a promover a construção do conhecimento de maneira ativa, criativa e crítica entre alunos e professores é um ponto importante a ser considerado. Pensando neste pressuposto, emerge uma questão: por que não aproveitar o acesso generalizado dos alunos aos diferentes recursos tecnológicos como via para as TDIC adentrar na sala de aula e tornar o processo de ensino e aprendizagem mais eficiente e eficaz?

Para responder a essa questão, é necessário que a escola faça parte desse novo contexto educacional, sendo fundamental incluir nas práticas educacionais o uso das TDIC, possibilitando a promoção de uma formação crítica dos alunos por meio do uso consciente e criativo destas ferramentas computacionais [Muller et al. 2016]. Segundo [ALDA 2012], para o uso efetivo das tecnologias em sala de aula, é preciso que haja uma reconstrução das práticas pedagógicas empregadas pelos professores, sendo necessário realizar escolhas conscientes acerca das tecnologias que poderão utilizar em suas aulas e que agreguem oportunidades de aprendizagem aos alunos no contexto escolar. Dessas escolhas decorrerão modos criativos e significativos de apropriação dos benefícios que as TDIC podem trazer para a educação. Considerando esses pressupostos, este trabalho tem o objetivo de investigar as concepções (diferentes possibilidades da utilização das TDIC como recurso didático em sala de aula, conhecimento dos recursos tecnológicos e das atividades que poderiam ser desenvolvidas com os mesmos dentro e fora do contexto educacional) dos professores do Ensino Fundamental das escolas municipais de uma cidade do Sul de Minas Gerais, em relação ao uso das TDIC nas suas práticas pedagógicas.

\section{Considerações Teóricas}

As transformações tecnológicas que se processam na atualidade exigem novos ritmos e dimensões frente à tarefa exercida pelo professor no processo de ensino e aprendizagem, como afirma [Moreira Kenski 2003]. Desse modo, refletir acerca das alterações feitas pelas TDIC nas práticas pedagógicas dos professores, implica pensar na formação desse profissional que não acontece apenas durante os cursos de formação de professores, mas durante todo o seu caminhar profissional, dentro e fora da sala de aula.

Abordar a formação do docente para trabalhar com as TDIC no ambiente escolar, não se restringe apenas à utilização de determinados equipamentos e produtos, mas também é preciso tratar das mudanças que ocorrem no trabalho e no comportamento dos docentes, provocadas pela introdução desses recursos tecnológicos [Freitas and Lima 2010]. De acordo com [de Oliveira 2015], o professor é visto como a figura fundamental no processo de ensino e aprendizado, porque as mudanças só entram na escola se for por seu intermédio. [Moran 2007] completa dizendo que à medida que a tecnologia avança, também devem existir docentes maduros intelectualmente, pessoas curiosas, abertas ao conhecimento e que saibam incentivar e dialogar com os alunos. Nessa direção, muitas vezes será necessário que os professores repensem e reconstruam as práticas pedagógicas utilizadas em prol do uso das TDIC. A esses atores do processo educativo cabe fazer escolhas conscientes das tecnologias que poderão utilizar em suas aulas, de acordo com o contexto escolar.

Segundo [Tezani 2011], por meio do uso das TDIC no contexto educacional, pro- 
VI Congresso Brasileiro de Informática na Educação (CBIE 2017)

Anais do XXIII Workshop de Informática na Escola (WIE 2017)

fessores e alunos poderão desenvolver competências e habilidades voltadas para as ações de comunicação, agilidades, busca de informação e autonomia individual, capazes de inseri-los na sociedade de informação e do conhecimento. Já [Garcia et al. 2012] completam com outras competências que os educadores precisam desenvolver para lidar com essas tecnologias. Essas competências podem ser distribuídas em quatro eixos, as quais são: 1) Competências tecnológicas, onde é necessário que os docentes tenham domínio para a seleção e utilização das TDIC de forma adequada; 2) Competências pedagógicas, onde é necessário que o docente desenvolva materiais, atividades e ambientes de ensino, condizentes com a realidade, o que implica em um despertar de interesse para uma participação ativa dos alunos; 3) Competências do sujeito, onde o docente deve compreender e valorizar as diferenças culturais existentes no contexto escolar e 4) Competências exploratórias, o docente, primeiramente, necessita compreender os diferentes níveis de aprendizagem dos alunos, ou seja, cada aluno tem suas próprias características, pontos fracos e fortes, que assinalam o processo de aprendizagem, enquanto os professores também tem características próprias do seu processo de ensinar.

As reflexões desenvolvidas até este ponto deixa claro que cabe aos professores integrarem o uso das TDIC em suas práticas pedagógicas e ao currículo escolar, de modo que consigam enriquecer o processo de ensino e aprendizagem dos alunos, tornando assim articuladores dessas novas formas de ensinar e aprender. Para tanto, estes docentes necessitam "superar barreiras administrativas e pedagógicas, para que consigam promover a transição de um sistema fragmentado de ensino para uma abordagem integradora" [Valente 2003]. Faz-se necessário, assim, a formação contínua do professor, no uso das TDIC em sala de aula, fazendo com que se tornem agentes construtores de uma nova forma de aprender e ensinar.

\section{Métodos}

Para atingir o objetivo descrito, optou-se pelo tipo de pesquisa qualitativa, quantitativa e exploratória, da qual tem como participante vinte e sete (27) professoras de seis (06) escolas municipais do Ensino Fundamental de uma cidade do Sul de Minas Gerais. A investigação ocorre em três fases, descritas abaixo.

Na primeira fase, as professoras conheceram os objetivos da pesquisa e responderam ao questionário I: "Perfil dos professores do Ensino Fundamental e suas Concepções sobre o uso das TDIC em sala de aula". O objetico desta fase foi conhecer o perfil das professoras e suas concepções acerca do uso das TDIC em sala de aula.

A segunda fase esta sendo composta pela realização de oficinas com uso das TDIC, constituídas por atividades envolvendo o uso dos aplicativos como: Faceboock, Whatsapp, Microsoft Word, Execel e Power Point e de alguns Objetos de Aprendizagem armazenados nos seguintes repositórios educacionais: Educopédia, Rede Interativa Virtual de Educação - RIVED, Banco Internacional de Objetos Educacionais - BIOE e do Grupo de Pesquisa e Produção de Ambientes Interativos e Objetos de Aprendizagem PROATIVA. Essas ferramentas tecnológicas foram selecionadas por permitirem que as professoras consigam refletir sobre como efetuar a integração dos conteúdos pedagógicos trabalhados em sala de aulas com as TDIC, o que pode facilitar o processo de ensino e aprendizagem escolar, por serem presente na vida social de muitos alunos. Em cada uma das oficinas, esta sendo entregue a cada professora apostilas com orientações e tutoriais 
VI Congresso Brasileiro de Informática na Educação (CBIE 2017)

Anais do XXIII Workshop de Informática na Escola (WIE 2017)

referentes ao uso dos aplicativos em questão. As oficinas estão acontecendo a cada quinze dias, ou seja, em uma semana as professoras participam da oficina e na outra elas aplicam o conteúdo estudado com seus alunos.

$\mathrm{Na}$ última fase da investigação aqui referida, as professoras participantes responderão ao questionário II "Concepções dos professores sobre o uso das TDIC nas suas práticas pedagógicas", que terá como objetivo coletar dados para serem comparados com os dados obtidos no primeiro questionário. Por fim, para a análise dos dados qualitativos coletados será utilizado aspectos da análise de conteúdo e os dados quantitativos será utilizado análise estatística.

\section{Considerações Finais}

As tecnologias marcam presença no cotidiano dos alunos inseridos em uma Era Digital em que fazem um constante uso de diversas ferramentas tecnológicas. No entanto, o que se pode notar é que o espaço educacional não está conseguindo oferecer a seus discentes e docentes um ambiente propício para que eles possam prover a construção de seu aprendizado, incluindo as tecnologias utilizadas fora da sala de aula. Assim, torna-se papel fundamental da escola e professores explorarem outras possibilidades em sala de aula, reforçando seu papel transformador para expandir as perspectivas e acompanhar as realizações dos alunos.

Por meio das oficinas, as professoras participantes da pesquisa estão tendo momentos de reflexão acerca da utilização das TDIC em suas práticas docentes. Durante as oficinas as participantes estão sendo incentivadas no sentido de usufruírem do potencial das tecnologias utilizadas, que podem ser auxiliares na inovação das metodologias de ensino em sala de aula, de modo a contribuir com a aprendizagem dos seus alunos. Os resultados parciais desta pesquisa, mostra que no decorrer das oficinas está sendo possível observar que as reações das professoras estão sendo marcadas por demonstrações de curiosidade, de medo, de ansiedade e de dúvida, o que evidencia que ao mesmo tempo em que estavam dispostas a adquirirem novos saberes, também se viam expostas às mudanças em suas concepções iniciais.

Pode-se notar ainda que a maioria das participantes possuí certa facilidade para trabalhar com as TDIC, não havendo muitas dificuldades por parte delas para entender as atividades propostas e realizá-las. No entanto, algumas docentes apresentam dificuldades em manusear os equipamentos computacionais como: mouse e o teclado, e também em relação ao uso dos aplicativos. As fragilidades percebidas até o momento estão relacionadas ao fato destas docentes nunca terem utilizado o computador, não possuírem computador em suas residências, utilizarem esporadicamente o uso das ferramentas computacionais ou nunca terem feito um curso básico de informática.

Tem-se ciência que as oficinas realizadas possam não suprirem todas as necessidades de formação para o uso das TDIC por essas professoras, para isso elas deverão buscar por novos cursos de formação continuada. Entretanto, o que se pode perceber é que as professoras participantes deste estudo se apresentam o tempo todo interessadas pelas atividades e conseguem envolver-se em questionamentos, discussões sobre os temas tratados e as TDIC utilizadas. Desse modo, ao que parece, conseguem entender como as TDIC podem representar uma nova maneira de conceber o conhecimento, provocando um redimensionamento dos conceitos básicos já conhecidos e possibilitando a busca e 
VI Congresso Brasileiro de Informática na Educação (CBIE 2017)

Anais do XXIII Workshop de Informática na Escola (WIE 2017)

compreensão de novas ideias por meio de discussões e reflexões. Espera-se que a análise dos dados colhidos por meio dos questionários aplicados traga indícios que permitam conhecer as concepções dos professores pesquisados, em relação ao uso das TDIC em suas práticas pedagógicas.

\section{Agradecimentos}

À FAPEMIG, pelo apoio para participação e apresentação do trabalho no Congresso Brasileiro de Informática da Educação (CBIE) de 2017. Ao IFSULDEMINAS campus Machado, MG, por disponibilizar a infraestrutura necessária para realização deste trabalho e pela concessão de uma bolsa de extensão de Ensino Superior.

\section{Referências}

ALDA, L. S. (2012). Novas tecnologias, novos alunos, novos professores? refletindo sobre o papel do professor na contemporaneidade. SEMINÁRIO INTERNACIONAL DE LETRAS, 12:1-6.

CGI.br. (2015). Pesquisa sobre o uso das tecnologias de informação e comunicação nos domicílios brasileiros. [Online. Acesso em 7 de abril de 2017].

de Oliveira, C. (2015). Tic's na educação: A utilização das tecnologias da informação e comunicação na aprendizagem do aluno. Pedagogia em Ação, 7(1).

Freitas, R. V. and Lima, M. S. S. (2010). As novas tecnologias na educação: desafios atuais para a prática docente. In Anais, pages 1-16. V Encontro de Pesquisa em Educação de Alagoas (epeal), Alagoas. [Online. Acesso em 20 de abril de 2017].

Garcia, M. F., Rabelo, D. F., da Silva, D., and do Amaral, S. F. (2012). Novas competências docentes frente às tecnologias digitais interativas. Teoria e Prática da Educação, 14(1):79-87.

Lima, B. C. d. (2015). O uso das tecnologias por alunos dos anos iniciais do ensino fundamental.

Moran, J. M. (2007). A educação que desejamos: novos desafios e como chegar lá. Papirus Editora.

Moreira Kenski, V. (2003). Aprendizagem mediada pela tecnologia. Revista diálogo educacional, 4(10).

Muller, E. E. R. et al. (2016). A importância dos recursos digitais no ambiente escolar.

Neitzel, L. C. (2008). A rede digital na rede educacional: um reencantamento. Localização:< http://www. geocities. com/neitzeluiz/reencan. html>. Acesso, 24(04).

Tezani, T. C. R. (2011). A educação escolar no contexto das tecnologias da informação e da comunicação (tic): desafios e possibilidades para a prática pedagógica curricular. Revista Faac, pages 36-45.

Valente, J. A. (2003). Formação de educadores para o uso da informática na escola. Pedro Ferreira de Andrade. 